\title{
(6) OPEN ACCESS \\ Doctors' enjoyment of their work and satisfaction with time available for leisure: UK time trend questionnaire-based study
}

\author{
Geraldine Surman, Trevor W Lambert, Michael Goldacre
}

\begin{abstract}
- Additional material is published online only. To view, please visit the journal online (http://dx.doi.org/10.1136/ postgradmedj-2015-133743).

UK Medical Careers Research Group, Nuffield Department of Population Health, University of Oxford, Oxford, UK
\end{abstract}

\section{Correspondence to} Trevor W Lambert, Unit of Health-Care Epidemiology, Nuffield Department of Population Health, University of Oxford, Old Road Campus, Old Road, Oxford OX7 3LF, UK: trevor.lambert@dph.ox.ac.uk

Received 21 September 2015 Revised 27 November 2015 Accepted 2 December 2015 Published Online First 18 January 2016

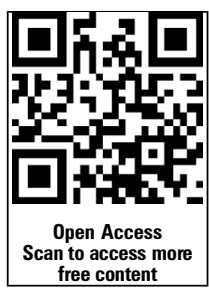

\section{SLinked}

- http://dx.doi.org/10.1136/ postgradmedj-2016-133961

\section{CrossMark}

To cite: Surman $\mathrm{G}$, Lambert TW, Goldacre M. Postgrad Med J

2016:92:194-200
ABSTRACT

Introduction Doctors' job satisfaction is important to the health service to ensure commitment, effective training, service provision and retention. Job satisfaction matters to doctors for their personal happiness, fulfilment, service to patients and duty to employers. Monitoring job satisfaction trends informs workforce planning.

Materials and methods We surveyed UK-trained doctors up to 5 years after graduation for six graduation year cohorts: 1996, 1999, 2002, 2005, 2008, 2012. Doctors scored their job enjoyment (Enjoyment) and satisfaction with time outside work (Leisure) on a scale from 1 (lowest enjoyment/satisfaction) to 10 (highest). Results Overall, $47 \%$ had a high level of Enjoyment (scores 8-10) 1 year after graduation and 56\% after 5 years. For Leisure, the corresponding figures were 19\% and $37 \%$ at 1 and 5 years, respectively. For Leisure at 1 year, high scores were given by about $10 \%$ in the 1990 s, rising to about $25 \%$ in the mid-2000s. Low scores (1-3) for Enjoyment were given by $15 \%$ of qualifiers of 1996 , falling to $5 \%$ by 2008 ; corresponding figures for Leisure were $42 \%$ and $19 \%$. At 5 years, the corresponding figures were $6 \%$ and $4 \%$, and $23 \%$ and $17 \%$. Enjoyment and Leisure were scored higher by general practitioners than doctors in other specialties. Both measures varied little by sex, ethnicity or medical school attended.

Conclusions Scores for Enjoyment were generally high; those for Leisure were lower. Policy initiatives should address why this aspect of satisfaction is low, particularly in the first year after graduation but also among hospital doctors 5 years after graduation.

\section{INTRODUCTION}

The training to become a doctor is long and demanding. It is expensive for both the individual trainee and for the public purse. The investment of time, effort and money begins to come to fruition when doctors qualify and commence work. However, if they do not achieve a level of satisfaction with their work that is appropriate for their level of commitment, the health service may risk of losing their valuable expertise ${ }^{12}$ to other countries or other careers. It is crucial to understand how doctors feel about their early experiences after graduation and to consider policy responses to mitigate any shortcomings. Having qualified as doctors but with further specialty training ahead, are they happy with their chosen careers? Do they enjoy their job, and are they satisfied with the time it leaves them for activities outside work?
Job enjoyment and satisfaction with the amount of time available for activities outside work are two elements particularly relevant to overall job satisfaction. ${ }^{1}$ Our aim in this paper is to report trends in doctors' self-assessed satisfaction with work and leisure 1 and 5 years after graduation, comparing successive cohorts of graduates, and to determine whether satisfaction varies between men and women, medical school attended or subsequent specialty of work 5 years after graduation.

\section{METHODS}

The surveys

The UK Medical Careers Research Group (MCRG) has undertaken multipurpose surveys of doctors about their careers for many years. ${ }^{3-10}$ MCRG surveys use self-completed postal and web-based questionnaires. The cohorts comprise all doctors from all UK medical schools in selected years of qualification. Doctors are contacted 1, 3 and 5 years after qualification and at varying intervals thereafter. Non-respondents are followed up with several reminders. Earlier papers describe our methods in detail. ${ }^{7} 11$

Data used for this analysis

We report results for six graduation years: 1996, 1999, 2002, 2005, 2008 and 2012. At the time of the surveys, respondents were either undertaking a common Foundation year, now called the 'F1 year' in the UK (graduates of 1996-2012), or were 5 years into their postgraduate careers (graduates of 1996-2008). Doctors completing questionnaires were deemed to have consented to the inclusion of their information in the study.

One year after graduation, we asked (among many other questions) How much have you enjoyed the F1 year overall? asking doctors to give a score on a scale from 1 (did not enjoy it at all) to 10 (enjoyed it greatly). We also asked How satisfied are you with the amount of time the F1 year has left you for family, social and recreational activities? scored from 1 (not at all satisfied) to 10 (greatly satisfied). In the surveys of the 1999 and 2002 cohorts, our questions referred to the PRHO (preregistration house officer) year. This was the term used for the first postgraduate training year prior to 2005. The 1996 graduation year doctors were asked to answer with reference to 'your current position', rather than the PRHO year.

Five years after graduation, all cohorts were asked How much are you enjoying your current position? and How satisfied are you with the amount of time your work currently leaves you for 
family, social and recreational activities? with responses scored in the same way as the year 1 surveys.

For brevity, we refer in the results, tables and figures to Enjoyment and Leisure to denote the two questions and the responses.

\section{Data analysis}

We compared scores for Enjoyment and Leisure using $\chi^{2}$ tests and rank-based non-parametric methods as appropriate.

\section{RESULTS}

\section{Survey responses: year 1}

From a graduation total of $29879 \mathrm{~F} 1$ doctors, we were able to contact 29184 doctors, of whom 56\% (16 440 doctors) replied to our surveys. We had no contact details for 692 doctors, and we knew of three deaths. A further 55 doctors were contacted but explicitly declined to take part. Late responders were given the option of abbreviated questionnaires which excluded the questions reported here. In all, 16298 doctors replied to the question about Enjoyment and 16286 to the question about Leisure.

\section{Survey responses: year 5}

A total of 21031 doctors out of 24447 were contactable, and 11841 replied (56\%). We had no contact details for 3386 . Thirty doctors were known to have died by the time of the year 5 survey and 218 declined to take part. A total of 11516 doctors replied to the question about Enjoyment and 11517 to the question about Leisure.

\section{Overall results for Enjoyment and Leisure}

Job enjoyment scores were arranged around a peak (modal) rating of 8 out of 10 with a long 'tail' of lower values (figure 1). Enjoyment ratings for year 1 surveys of graduates from the earlier cohort years studied $(1996,1999)$ were lower than others. By year 5, there was little visible difference between the cohorts in Enjoyment (figure 1B) with all scores peaking at 8 out of 10. Kruskal-Wallis one-way analysis of variance on the Enjoyment scores gave a much higher test statistic for the year 1 surveys $\left(\chi_{5}^{2}=2278.9\right)$ than for the year 5 surveys $\left(\chi_{4}^{2}=983.4\right)$ indicating a greater degree of variation between the cohorts in the scores-though both tests gave $\mathrm{p}<0.001$.

The profile for Leisure score ratings was somewhat different (figure 2). For year 1 surveys, the earlier the cohort, the lower Leisure tended to be rated. Doctors in the 1996 and 1999 cohorts rated their Leisure time at a peak of around 3-4 compared with a peak rating of 7 in the more recent cohorts. As with Enjoyment, the pattern of ratings for Leisure in the year 5 surveys was similar for all cohorts, peaking around 8 out of 10 although 1996 graduates were bimodal at a score of 3-4 and a score of 7. Kruskal-Wallis tests confirmed that the Leisure scores differed significantly by year of graduation $\left(\chi_{5}^{2}=2414.8\right.$, $\mathrm{p}<0.001$ for the year 1 surveys and $\chi_{4}^{2}=1216.5, \mathrm{p}<0.001$ for the year 5 surveys).

For convenience of further analysis, responders' ratings of their Enjoyment and Leisure were grouped as Low (1-3), Medium (4-7) and High (8-10). In year 1, over all cohorts, $47 \%$ had a high level of enjoyment, $47 \%$ a medium and $7 \%$ a low level (table 1). The Leisure satisfaction rating was less positive, with only $19 \%$ recording a high score, $56 \%$ medium and $27 \%$ low. As table 1 shows, there was a general trend for Enjoyment scores to improve with each subsequent cohort. Enjoyment scores at year 5 were markedly higher than for the same cohort at year 1 .
Leisure scores exhibited a similar pattern of improvement across the cohorts with the exception of the 2012 cohort in year 1 which showed a slight decrease in satisfaction compared with the 2009 cohort. Although Leisure scores showed considerable improvement in year 5 compared with year 1 , they were lower than Enjoyment scores in all cohorts (table 1).

\section{Changes between years 1 and 5}

Doctors' scores for Enjoyment and Leisure changed significantly between years 1 and 5: for Enjoyment and Leisure, respectively, the McNemar-Bowker test statistic for changes between the three rating categories was 239.6 and 943.1 (both $\mathrm{p}<0.001$ ).

Only $11 \%$ of doctors (67/601) who scored their Enjoyment as Low in year 1 still scored it as Low at year 5 (table 2). Sixty-five per cent of doctors (2710/4196) who recorded a High score at year 1 retained a High score at year 5. Overall, 29\% (2677/9227) improved their score and 18\% (1693/9227) reported a worse score at year 5 .

Doctors' Leisure scores improved less than their Enjoyment scores, with 24\% (596/2492) in the Low category in both year 1 and year 5 surveys and 45\% (722/1618) retaining a year 1 High score in year 5. Overall, 40\% (3727/9226) had improved and $18 \%(1639 / 9226)$ scored worse at year 5 .

Differences in scores between men and women, and between doctors of different ethnicities were small (see online supplementary appendix A and B).

\section{Differences by country and by medical school attended (year 1 only)}

Medical schools attended were grouped by UK country, and within England into London, Oxford and Cambridge, new English schools and older English schools (see online supplementary appendix C). Enjoyment of the F1 year did not vary significantly by country (table 3). Satisfaction with Leisure varied significantly by country. Wales had the greatest proportion of doctors scoring their satisfaction with their Leisure time as High, followed by England, Scotland and Northern Ireland.

\section{Differences by specialty (year 5 only)}

By year 5, doctors were working in a designated specialty and Enjoyment and Leisure scores could be compared by specialty. Specialties were grouped as described in online supplementary appendix D. Enjoyment scores did not vary greatly between the four specialty groups (table 4) in percentage satisfaction, though the variation was statistically significant.

Scores for Leisure varied much more by specialty and were the highest among respondents in general practice.

\section{DISCUSSION}

\section{Main findings}

Doctors in these cohorts were generally positive about their level of enjoyment of their first postgraduate year with only a very small percentage reporting a low level of enjoyment. Graduates from the four cohorts we surveyed who graduated between 2002 and 2012 scored consistently high for enjoyment; results from graduates of the 1990s were somewhat lower. Doctors in all cohorts were less satisfied with the amount of time their job allowed them for non-work activities, with many scores around the midpoint of our scale, though, as was the case for job enjoyment, scores for recent graduates were higher than for those from the 1990s. The fact that Enjoyment scores tended to be much higher than Leisure scores needs consideration. It is possible that high levels of job satisfaction to some extent compensate for long and sometimes unsocial hours, 


\section{Original article}

Figure 1 How doctors score job year after graduation, graduates of 1996-2012 and (B) 5 years after graduation, graduates of 1996-2008. enjoyment out of 10 in $(A)$ their first
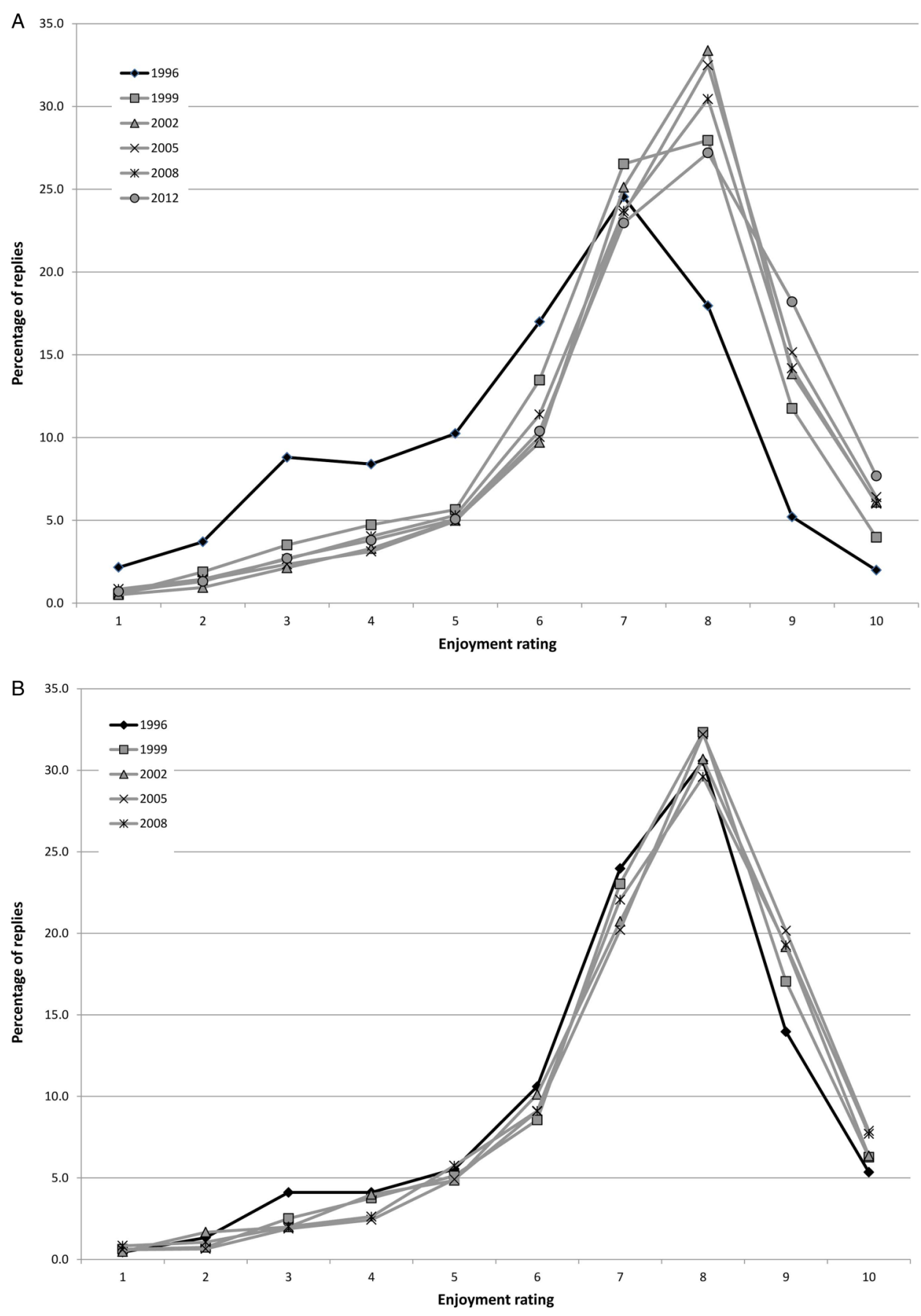

though we have no data from this study which demonstrate that this is the case.

The secular trend on both measures was one of increasing satisfaction. The improvement at year 1 broadly coincided with the introduction of the European Working Time Directive (EWTD) in 2005, though it is beyond the scope of this study to attribute causation. Differences in scores between men and women, and between doctors from different ethnic groups were small. Analysis by medical school attended did not reveal large variation, though within schools, the satisfaction levels for enjoyment and leisure time satisfaction tended to be related.

When surveyed 5 years after graduation, both Enjoyment and Leisure scores had improved substantially, although leisure time satisfaction at 5 years did not appear to have improved among doctors surveyed after the introduction of the EWTD as much as might have been expected. Doctors in general practice scored their Enjoyment and Leisure higher than did doctors in other specialties.

\section{Strengths and weaknesses of the study}

This is a large study with the capability for studying junior doctors' views over many graduation cohorts, with questions asked in a consistent format to maintain comparability. The range and detail of questions was necessarily limited in order to maximise response rates. In common with all surveys, there is potential for non-responder bias. 

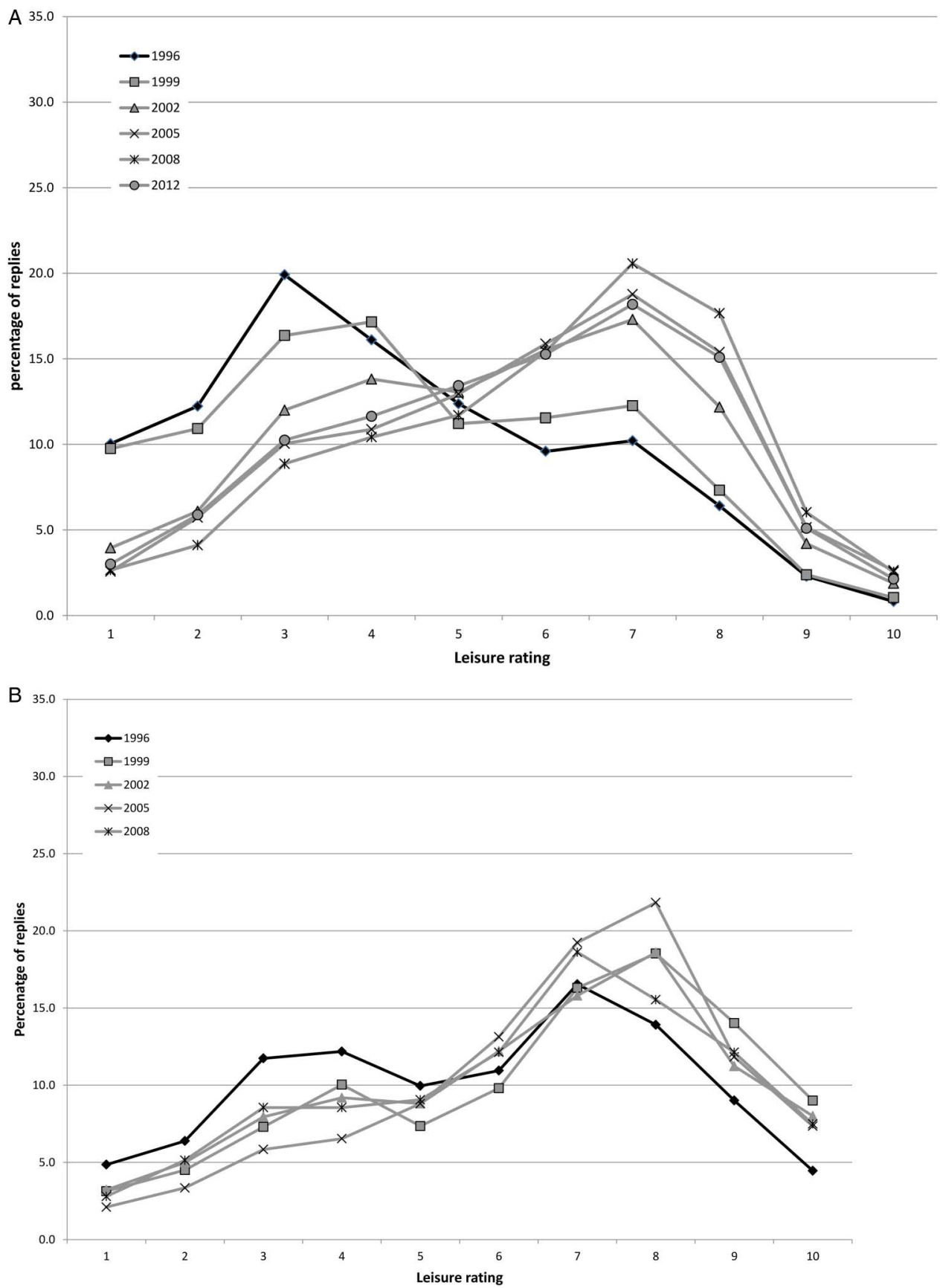

Figure 2 How doctors score leisure time out of 10 in (A) their first year after graduation, graduates of 1996-2012, and (B) 5 years after graduation, graduates of 1996-2005.

Self-perceived enjoyment does not necessarily relate to competence, or to the value of a learning experience, or to being a marker of the ability of the new doctor to make a positive contribution in the workplace. Satisfaction with leisure time is necessarily a subjective measure, and respondents will have differing expectations and requirements. It does not necessarily directly reflect the actual hours worked relative to those expected. Nevertheless, both measures have value in indicating the level of satisfaction of junior doctors with their early postgraduate years of work.

\section{National and international context}

Doctors who graduated in 2008 scored their job enjoyment slightly lower than graduates of 2002 and 2005 in our year 1 survey. Bovier and Perneger showed general job satisfaction for
Swiss doctors to have decreased in their study of $2007 . .^{12}$ We found job enjoyment scores had increased marginally for the 2002 and 2005 graduates compared with earlier years. Aasland et $a l,{ }^{13}$ in a study of doctors in Norway, showed job satisfaction increased over a similar period (2000-2006). Job enjoyment for doctors is probably complex, a result of several factors that vary from doctor to doctor and will include the quality of their interaction with others in the team such as nursing staff. ${ }^{14}$ Nursing staff generally provide core stability to any hospital team. Doctors in training spend short periods in several different teams and how much doctors enjoy their work may vary with the post and, in particular, how well they are integrated into a new team. Variation by medical school in the enjoyment of the F1 year may reflect in part different support environments found in different Trusts. 
Table 1 Enjoyment and Leisure: doctors' views 1 and 5 years after qualification, percentages of those who replied

\begin{tabular}{|c|c|c|c|c|}
\hline & \multicolumn{3}{|c|}{ Percentage level of satisfaction* } & \multirow[b]{3}{*}{$\begin{array}{l}\text { Total replies } \\
(100 \%)\end{array}$} \\
\hline & \multicolumn{3}{|c|}{ Responder rating out of 10} & \\
\hline & $\begin{array}{l}\text { Low } \\
(1-3)\end{array}$ & $\begin{array}{l}\text { Medium } \\
(4-7)\end{array}$ & $\begin{array}{l}\text { High } \\
(8-10)\end{array}$ & \\
\hline \multicolumn{5}{|l|}{ Enjoyment } \\
\hline \multicolumn{5}{|l|}{ Year $1 \dagger$} \\
\hline 1996 & 14.7 & 60.2 & 25.2 & 2918 \\
\hline 1999 & 5.9 & 50.4 & 43.7 & 2390 \\
\hline 2002 & 3.6 & 43.1 & 53.3 & 2760 \\
\hline 2005 & 4.3 & 41.6 & 54.0 & 3109 \\
\hline 2008 & 5.0 & 44.4 & 50.6 & 2828 \\
\hline 2012 & 4.7 & 42.2 & 53.1 & 2291 \\
\hline All years & 6.5 & 47.0 & 46.5 & 16296 \\
\hline \multicolumn{5}{|l|}{ Year $5 \ddagger$} \\
\hline 1996 & 6.2 & 43.6 & 50.2 & 2231 \\
\hline 1999 & 4.0 & 40.6 & 55.5 & 2353 \\
\hline 2002 & 4.3 & 39.6 & 56.1 & 2242 \\
\hline 2005 & 3.3 & 37.3 & 59.4 & 2255 \\
\hline 2008 & 4.2 & 39.5 & 56.4 & 2306 \\
\hline All years & 4.4 & 40.1 & 55.5 & 11387 \\
\hline \multicolumn{5}{|l|}{ Leisure } \\
\hline \multicolumn{5}{|l|}{ Year 1§ } \\
\hline 1996 & 42.2 & 48.3 & 9.5 & 2918 \\
\hline 1999 & 37.0 & 52.2 & 10.8 & 2389 \\
\hline 2002 & 22.0 & 59.7 & 18.3 & 2758 \\
\hline 2005 & 18.4 & 58.5 & 23.2 & 3106 \\
\hline 2008 & 15.6 & 58.1 & 26.2 & 2820 \\
\hline 2012 & 19.1 & 58.5 & 22.3 & 2293 \\
\hline All years & 25.6 & 55.9 & 18.5 & 16284 \\
\hline \multicolumn{5}{|l|}{ Year 5ף } \\
\hline 1996 & 22.8 & 49.5 & 27.8 & 2230 \\
\hline 1999 & 15.5 & 43.3 & 41.3 & 2353 \\
\hline 2002 & 16.7 & 45.8 & 37.5 & 2245 \\
\hline 2005 & 11.8 & 46.9 & 41.2 & 2256 \\
\hline 2008 & 17.0 & 47.2 & 35.8 & 2304 \\
\hline All years & 16.7 & 46.5 & 36.8 & 11388 \\
\hline \multicolumn{5}{|c|}{$\begin{array}{l}\text { *Scored from } 1 \text { (not at all satisfied) to } 10 \text { (highly satisfied) and grouped. } \\
\text { tLinear-by-linear association was significant at } 500.5, \mathrm{p}<0.001 \text {. } \\
\text { fLinear-by-linear association was significant at } 29.1, \mathrm{p}<0.001 \text {. } \\
\text { \$Linear-by-linear association was significant at } 776.6, \mathrm{p}<0.001 \text {. } \\
\text { qLinear-by-linear association was significant at } 42.5, \mathrm{p}<0.001 \text {. }\end{array}$} \\
\hline
\end{tabular}

Doctors' enjoyment of their work was maintained and even very slightly increased despite the UK recession of 2008 and challenging financial circumstances for the National Health Service. During 2005, the previous training programme was replaced by Modernising Medical Careers (MMC). ${ }^{15}$ Under MMC, the first two postgraduate years became more structured and the learning targets became more specific. Enjoyment scores for 2005 were similar to 2002 and have fluctuated a little for subsequent cohorts of junior doctors but, overall, the change in training regime, although significant, appears to have had little immediate impact on new graduates' enjoyment of their first year. Doctors' attitudes reflect the surprisingly high levels of job satisfaction across all UK occupations during the recent difficult years for the UK economy. It has been mooted that, in times of financial crisis, expectations may be lowered ${ }^{16}$ and this, in turn, could result in higher than expected job satisfaction.

A survey of Specialist Registrars attending a UK Obstetrics and Gynaecology meeting found that only half the respondents felt
Table 2 Enjoyment and Leisure: how doctors' views changed between 1 and 5 years after graduation

\begin{tabular}{lcccc}
\hline & \multicolumn{2}{l}{ Year 5 survey } & \\
\cline { 2 - 3 } & $\begin{array}{l}\text { Low } \\
(1-3)\end{array}$ & $\begin{array}{l}\text { Medium } \\
(4-7)\end{array}$ & $\begin{array}{l}\text { High } \\
(8-10)\end{array}$ & $\begin{array}{l}\text { Total (numbers } \\
\text { who replied) }\end{array}$ \\
\hline Year 1 survey & & & & \\
Enjoyment & & & & \\
$\quad$ Low (1-3) & 67 & 260 & 274 & 601 \\
$\quad$ Medium (4-7) & 207 & 2080 & 2143 & 4430 \\
High (8-10) & 117 & 1369 & 2710 & 4196 \\
$\quad$ Total (replied) & 391 & 3709 & 5127 & 9227 \\
Leisure & & & & \\
$\quad$ Low (1-3) & 596 & 1099 & 797 & 2492 \\
$\quad$ Medium (4-7) & 743 & 2542 & 1831 & 5116 \\
High (8-10) & 186 & 710 & 722 & 1618 \\
Total (replied) & 1525 & 4351 & 3350 & 9226 \\
\hline
\end{tabular}

they had achieved work-life balance. ${ }^{17}$ Our scores on satisfaction with the amount of time available for leisure show a similar mixed picture. Dissatisfaction with time for social and family life were the greatest factors for those who felt they had not achieved balance. ${ }^{17}$ A survey by the Medical Workforce Unit at the Royal College of Physicians also found variation in the rating of work-life balance among registrars in different specialties, with general practice registrars having the highest scores. ${ }^{18}$ In the USA, general surgeons were found to have significantly poorer work-life balance than doctors in other specialties, ${ }^{19}$ which concurs with our findings. A comparison of the job satisfaction of hospital doctors in Germany and Norway found significant differences between the two countries. ${ }^{20}$ Job satisfaction among New Zealand doctors compared with those in the UK has been traditionally reported as higher. ${ }^{21}$

The EWTD was introduced to medicine in the UK from 2005. In principle, it restricts the working week to an average

Table 3 Enjoyment and Leisure: doctors' views according to their medical school, 1 year after graduation

\begin{tabular}{|c|c|c|c|c|}
\hline \multirow[b]{2}{*}{$\begin{array}{l}\text { Medical School } \\
\text { group }\end{array}$} & \multicolumn{4}{|c|}{ Percentage responder rating out of 10} \\
\hline & $\begin{array}{l}\text { Low } \\
(1-3)\end{array}$ & $\begin{array}{l}\text { Medium } \\
(4-7)\end{array}$ & $\begin{array}{l}\text { High } \\
(8-10)\end{array}$ & $\begin{array}{l}\text { Total replies } \\
(100 \%)\end{array}$ \\
\hline \multicolumn{5}{|l|}{ Enjoyment* } \\
\hline England Old & 4.2 & 43.4 & 52.4 & 2260 \\
\hline England New & 4.9 & 44.0 & 51.2 & 473 \\
\hline England London & 5.0 & 44.7 & 50.3 & 1097 \\
\hline England Oxbridge & 6.6 & 46.7 & 46.7 & 289 \\
\hline Scotland & 7.1 & 41.6 & 51.3 & 606 \\
\hline Wales & 3.3 & 41.1 & 55.6 & 241 \\
\hline Northern Ireland & 3.2 & 38.3 & 58.4 & 154 \\
\hline \multicolumn{5}{|l|}{ Leisuret } \\
\hline England Old & 15.2 & 58.7 & 26.2 & 2256 \\
\hline England New & 19.7 & 55.0 & 25.3 & 471 \\
\hline England London & 18.5 & 57.4 & 24.1 & 1095 \\
\hline England Oxbridge & 19.3 & 60.7 & 20.0 & 290 \\
\hline Scotland & 21.6 & 57.2 & 21.3 & 607 \\
\hline Wales & 14.9 & 58.9 & 26.1 & 241 \\
\hline Northern Ireland & 13.0 & 68.2 & 18.8 & 154 \\
\hline
\end{tabular}


Table 4 Enjoyment and Leisure: doctors' views according to their current specialty 5 years after graduation

\begin{tabular}{|c|c|c|c|c|}
\hline \multirow[b]{2}{*}{ Specialty group } & \multicolumn{4}{|c|}{ Percentage responder rating out of 10} \\
\hline & $\begin{array}{l}\text { Low } \\
(1-3)\end{array}$ & $\begin{array}{l}\text { Medium } \\
(4-7)\end{array}$ & $\begin{array}{l}\text { High } \\
(8-10)\end{array}$ & $\begin{array}{l}\text { Total replies } \\
(100 \%)\end{array}$ \\
\hline \multicolumn{5}{|l|}{ Enjoyment* } \\
\hline $\begin{array}{l}\text { Medical specialties/hospital } \\
\text { medicine }\end{array}$ & 4.8 & 42.6 & 52.6 & 2028 \\
\hline Surgery & 5.3 & 40.8 & 53.9 & 2219 \\
\hline Other specialties combined & 4.1 & 38.5 & 57.4 & 3202 \\
\hline General practice & 3.5 & 39.8 & 56.6 & 2962 \\
\hline \multicolumn{5}{|l|}{ Leisuret } \\
\hline $\begin{array}{l}\text { Medical specialties/hospital } \\
\text { medicine }\end{array}$ & 19.0 & 47.9 & 33.1 & 2028 \\
\hline Surgery & 23.0 & 49.8 & 27.2 & 2220 \\
\hline Other specialties combined & 19.7 & 50.5 & 29.8 & 3206 \\
\hline General practice & 8.2 & 41.4 & 50.5 & 2961 \\
\hline
\end{tabular}

of $48 \mathrm{~h}$ and prescribes rest periods and annual periods of paid leave. While EWTD may have contributed to our finding marginally higher leisure time satisfaction scores from 2005 onwards among the F1 doctors, scores had already markedly improved in 2002 compared with 1996 and 1999. In a small qualitative study in the USA in 2004, it was found that while the introduction of fixed working time resulted in 'an improved sense of well-being' among doctors, concern about discontinuity of patient care and missed learning opportunities left them generally dissatisfied. ${ }^{22}$ Across all occupations in Britain, satisfaction with work and work-life balance improved between 2006 and 2010, although the workers in the UK score lower than the workers in most European countries. ${ }^{16}$

In our surveys, leisure satisfaction scores of F1 doctors have increased steadily in successive cohorts. Lydall et al's ${ }^{23}$ findings of a 2007 study of applicants to the newly introduced Medical Training Application System (MTAS), a short-lived online job application system that was beset by implementation problems, reported high levels of depressive symptoms at that time. Fortunately, the stress that most junior doctors would have suffered and which may have affected their job enjoyment appears to have attenuated, and proportions reporting high scores for both enjoyment and leisure satisfaction in our most recent surveys are either equal to, or greater than, pre-MTAS levels.

As with this study, Bovier and Perneger ${ }^{24}$ found scores for enjoyment to be higher than for satisfaction with leisure time in a survey in 1998 and a random sample of 2000 doctors in the USA reported in 2007 found that overall job satisfaction may be high even though work-life balance is poor. ${ }^{19}$ A 2012 Israeli study of neonatologists also found high levels of job satisfaction alongside low levels of satisfaction with workload and leisure time. ${ }^{25}$ In his commentary on Moshe et al's paper, Kravitz remarks that 'physician satisfaction is a public health issue'. ${ }^{26}$

We were concerned that doctors' enjoyment of their work in their first year after graduation may reflect some aspects of their experiences during their time at medical school. It should be noted that some junior doctors travel to gain experience in institutions away from their original medical school and the views they express will relate to this new institution. Generally, the differences in scores for both Enjoyment and Leisure by medical school attended prior to graduation were small, which may reflect this mobility. Differences in enjoyment and leisure time satisfaction, comparing graduates of different medical schools, were not as pronounced as differences in the level of (selfperceived) preparedness for practice by medical school, on which we have previously published. ${ }^{27-31}$

We found only small differences in scores for both enjoyment and leisure between men and women, and between doctors from different ethnic groups. These findings are similar to both Keeton $e t a l^{19}$ in the USA and Aasland et $a l^{13}$ in Norway.

\section{CONCLUSIONS}

Doctors' job enjoyment and satisfaction with leisure time fluctuated but results indicate a trend of improving scores over the whole period studied. The latest data we report show that satisfaction with leisure time remains low despite it being a decade since the implementation of the EWTD in the UK. Differences in scores according to medical school attended, sex and ethnicity were slight. Doctors in general practice 5 years after graduation rated their Enjoyment and Leisure higher than doctors in other specialties.

Adequate leisure time is an important component of overall job satisfaction, yet it was common for doctors to score this lower than their job enjoyment. Policy initiatives should address why this aspect of satisfaction is so low, particularly in the first year after graduation, and among hospital doctors 5 years after graduation.

\section{Main messages}

- Results indicate a trend of improving scores for both Enjoyment and Leisure over the whole period studied.

- Satisfaction with leisure time remains low despite the implementation of the European Working Time Directive.

- Factors such as gender, ethnicity and medical school attended do not significantly affect doctors' views on their Enjoyment or Leisure.

- Doctors in general practice 5 years after graduation rated their Enjoyment and Leisure higher than doctors in other specialties.

- Policy initiatives should address why satisfaction with Leisure time is so low, particularly in the first year after graduation, and among hospital doctors 5 years after graduation.

\section{Current research questions}

- Why is satisfaction with Leisure time so low, 10 years after the implementation of the European Working Time Directive?

- Why are job enjoyment and Leisure satisfaction higher for general practitioners than for hospital doctors?

- Why do year 1 scores for Enjoyment and Leisure remain consistently below year 5 scores?

Acknowledgements We thank Janet Justice and Alison Stockford for data entry. We are very grateful to all the doctors who participated in the surveys. 
Contributors All authors are guarantors. All authors had full access to all the data (including statistical reports and tables) in the study and take responsibility for the integrity of the data and the accuracy of the data analysis. MG and TWL planned and designed the surveys. All authors planned the data analysis. GS and TWL undertook the data analysis. TWL provided statistical support. GS wrote the first draft of the paper. All authors contributed to further drafts and approved the final version.

Funding This is an independent report commissioned and funded by the Policy Research Programme in the Department of Health (project number 016/0118).

Competing interests None declared.

Ethics approval National Research Ethics Service, following referral to the Brighton and Mid-Sussex Research Ethics Committee in its role as a multicentre research ethics committee (ref 04/Q1907/48 amendment Am02 March 2015).

Provenance and peer review Not commissioned; externally peer reviewed.

Data sharing statement It may be possible for the authors to make tabulated data, produced in the course of this work but not included in the paper, available to interested readers on request.

Open Access This is an Open Access article distributed in accordance with the Creative Commons Attribution Non Commercial (CC BY-NC 4.0) license, which permits others to distribute, remix, adapt, build upon this work non-commercially, and license their derivative works on different terms, provided the original work is properly cited and the use is non-commercial. See: http://creativecommons.org/ licenses/by-nc/4.0/

\section{REFERENCES}

1 Coomber B, Barriball KL. Impact of job satisfaction components on intent to leave and turnover for hospital-based nurses: a review of the research literature. Int J Nurs Stud 2007;44:297-314.

2 Sharma A, Lambert TW, Goldacre MJ. Why UK-trained doctors leave the UK: cross-sectional survey of doctors in New Zealand. J $R$ Soc Med 2012;105:25-34.

3 Taylor K, Lambert T, Goldacre M. Career destinations, job satisfaction and views of the UK medical qualifiers of 1977. J R Soc Med 2008;101:191-200.

4 Taylor K, Lambert T, Goldacre M. Career destinations, views and future plans of the UK medical qualifiers of 1988. J $R$ Soc Med 2010;103:21-30.

5 Lambert TW, Goldacre MJ. Doctors' views about their first postgraduate year in UK medical practice: house officers in 2003. Med Educ 2006;40:1115-22.

6 Goldacre MJ, Davidson JM, Lambert TW. Doctors' views of their first year of medical work and postgraduate training in the UK: questionnaire surveys. Med Educ 2003;37:802-8.

7 Lambert TW, Goldacre MJ, Edwards C, et al. Career preferences of doctors who qualified in the United Kingdom in 1993 compared with those of doctors qualifying in 1974, 1977, 1980, and 1983. Brit Med J 1996;313:19-24.

8 Goldacre M, Stear S, Richards R, et al. Junior doctors' views about careers in academic medicine. Med Educ 1999;33:318-26.

9 Goldacre MJ, Lambert TW. Participation in medicine by graduates of medical schools in the United Kingdom up to 25 years post graduation: national cohort surveys. Acad Med 2013;88:699-709.

10 Lambert TW, Surman G, Goldacre MJ. Views of UK-trained medical graduates of 1999-2009 about their first postgraduate year of training: national surveys. BMJ Open 2013;3:e002723.
11 Goldacre MJ, Davidson JM, Lambert TW. Career choices at the end of the pre-registration year of doctors who qualified in the united kingdom in 1996. Med Educ 1999;33:882-9.

12 Perneger TV, Deom M, Cullati S, et al. Growing discontent of Swiss doctors, 19982007. Eur J Public Health 2012;22:478-83.

13 Aasland OG, Rosta J, Nylenna M. Healthcare reforms and job satisfaction among doctors in Norway. Scand J Public Health 2010;38:253-8.

14 Krogstad U, Hofoss D, Veenstra M, et al. Predictors of job satisfaction among doctors, nurses and auxiliaries in Norwegian hospitals: relevance for micro unit culture. Hum Resour Health 2006;4:3

15 Delamothe T. Modernising medical careers: final report. BMJ 2008;336:54-5.

16 McManus SPJ. British Social Attitudes 29. British Social Attitudes [serial on the Internet]. 2012. http://www.bsa-29.natcen.ac.uk/media/13421/bsa29_full_report. pdf

17 Thangaratinam S, Yanamandra SR, Deb S, et al. Specialist training in obstetrics and gynaecology: a survey on work-life balance and stress among trainees in UK. J Obstet Gynaecol 2006;26:302-4.

18 Chaudhuri E, Mason NC, Newbery N, et al. Career choices of junior doctors: is the physician an endangered species? Clin Med 2013;13:330-5.

19 Keeton K, Fenner DE, Johnson TR, et al. Predictors of physician career satisfaction, work-life balance, and burnout. Obstet Gynecol 2007;109:949-55.

20 Rosta J, Nylenna M, Aasland OG. Job satisfaction among hospital doctors in Norway and Germany. A comparative study on national samples. Scand J Public Health 2009;37:503-8.

21 Grant P. Physician job satisfaction in New Zealand versus the United Kingdom. N Z Med J 2004;117:U1123.

22 Lin GA, Beck DC, Garbutt JM. Residents' perceptions of the effects of work hour limitations at a large teaching hospital. Acad Med 2006;81:63-7.

23 Lydall GJ, Malik A, Blizard R, et al. Psychological impact of systemic training failure on mental health and career satisfaction of UK trainees: lessons from an online attitudes survey. Int J Soc Psychiatry 2009;55:180-90.

24 Bovier PA, Perneger TV. Predictors of work satisfaction among physicians. Eur J Public Health 2003;13:299-305.

25 Moshe M, Perry ZH, Salzer L, et al. Work satisfaction, quality of life, and leisure time of neonatology fellows and senior neonatologists in Israel. Isr J Health Policy Res 2012;1:50

26 Kravitz RL. Physician job satisfaction as a public health issue. Isr I Health Policy Res 2012;1:51.

27 Svirko E, Lambert T, Goldacre MJ. Gender, ethnicity and graduate status, and junior doctors' self-reported preparedness for clinical practice: national questionnaire surveys. J R Soc Med 2014;107:66-74.

28 Goldacre MJ, Lambert TW, Svirko E. Foundation doctors' views on whether their medical school prepared them well for work: UK graduates of 2008 and 2009. Postgrad Med J 2014;90:63-8

29 Goldacre MJ, Taylor K, Lambert T. Views of junior doctors about whether their medical school prepared them well for work: questionnaire surveys. BMC Med Educ 2010;10:78.

30 Cave J, Goldacre M, Lambert TW, et al. Newly qualified doctors' views about whether their medical school had trained them well: questionnaire surveys. BMC Med Educ 2007;7:38.

31 Goldacre MJ, Lambert T, Evans J, et al. Pre-registration house officers views on whether their experience at medical school prepared them well for their jobs: national questionnaire survey. BMJ 2003;326:1011-12. 